\title{
ESTRATÉGIAS DE INSERÇÃO NO MERCADO INTERNACIONAL: ESTUDO DE CASO DA TOLI
}

\section{Priscilla Dantas Ribeiro Teixeira}

Graduada em Comércio Exterior pelo Instituto Federal de Educação, Ciência e Tecnologia do RN; Discente do $10^{\circ}$ período de Direito da Universidade Federal do RN; Membro da

Comissão de Relações Internacionais da OAB/ RN. Priscilladantas85@ hotmail.com

\section{Gerda Lúcia Pinheiro Camelo}

Professora Orientadora

Possui mestrado em Gestão e Políticas Públicas pela Universidade Federal do Rio Grande do Norte (2001). Especializações em Gestão da Qualidade Total pela Universidade Federal do RN (1999), Comércio Exterior com ênfase em pequenas empresas pela Universidade Católica de Brasília (2004) e em Educação de Jovens e Adultos pelo Centro Federal de Educação Tecnológica do Rio Grande do Norte (2007).gerda@ cefetrn.br

\section{RESUMO}

O presente projeto faz considerações acerca da empresa Toli, inserida no segmento de moda feminina, no mercado norte riograndense e brasileiro, bem como as peculiaridades de sua possível inserção no mercado externo. Tem como objetivo principal traçar a partir da análise da gestão interna, estratégias de inserção da empresa no cenário internacional. Para a consecução deste objetivo, foi realizado um estudo de caso privilegiando uma análise da estrutura organizacional da empresa referida, focando os diversos setores e suas inter-relações, bem como a identificação das limitações e vantagens competitivas existentes no cerne do cenário exterior. Os procedimentos metodológicos utilizam-se de pesquisas bibliográficas, documental e de campo, onde foram coletados dados através de um questionário semi-estruturado e/ou entrevista respondidas pelos responsáveis pela empresa Toli, localizada na cidade de Natal e atuante de destaque no setor de moda feminina. Os resultados obtidos possibilitaram fazer uma análise qualitativa dos dados obtidos e observar os elementos que levam a empresa a ser destaque no mercado em que atua.

PALAVRAS-CHAVE: Empresa Toli, Exportação - Mercado Internacional, Estratégia.

\section{STRATEGIES FOR ENTERING IN THE INTERNATIONAL MARKET - A STUDY CASE OF TOLI}

\begin{abstract}
This project studies the Toli company, inserted in the segment of feminine fashion, at rio grande do norte's and brazilian's market, as well as the peculiarities of its possible entrance in the international market. This paper work's goal is to establish, from the analysis of the internal management structor strategies of insertion of the company in the international scene. In order to achieve this goal, will be carried through a study case, privileging an analysis of the organizacional structure of the related company, focusing all sectors and it's inter-relations. The study it will be carried through by gathering information gotten through bibliographical research, documentary and of field research, collected through a pre-structuralized questionnaire and/or interview to be answered by the
\end{abstract}


responsible ones of Toli. With the port theoretical and the information that will be gotten through the questionnaire and/or interviews, it will be possible to make a qualitative analysis and observ the elements that make the company prominence in the norteast and brazilian's market.

Key words: Toli, Export - International Market and Strategy.

\section{ESTRATÉGIAS DE INSERÇÃO NO MERCADO INTERNACIONAL: ESTUDO DE CASO DA TOLI}

\section{INTRODUÇÃO}

No cenário atual de constantes mudanças de ordem social, econômica, produtiva e política, vislumbra-se a globalização como fator determinante para a interdependência de todos os povos e países do nosso planeta, com ênfase num processo de integração de economias e mercados nacionais, transformando o mundo numa verdadeira "aldeia global".

Em face da globalização das economias, com os mercados internos saturados, muitas empresas buscaram conquistar novos mercados consumidores, gerando uma concorrência extremamente competitiva, fazendo com que as empresas utilizem cada vez mais recursos tecnológicos para baratear os preços e também para estabelecerem contatos comerciais e financeiros de forma rápida e eficiente.

Vale salientar que esse processo gerou uma intensa revolução nas tecnologias, que têm sido fundamentais para agilizar o comércio e as transações financeiras entre os países.

Como observa Farah Júnior (1999), historicamente, a realidade brasileira no âmbito das atividades econômicas foi voltada, para o modelo de substituição de importações para atender à demanda interna. Com o advindo da globalização e da abertura de mercados esta realidade foi drasticamente mudada, exigindo-se o preparo das empresas brasileiras para esta nova etapa de competição econômica, cultural e tecnológica, que já se apresenta de forma intensa e crescente, sendo necessário implementar estratégias de crescimento empresarial condizentes com os novos desafios.

Neste cenário enquadra-se a empresa a ser estudada, a Toli. Criada em 1992, a empresa hoje é destaque no mercado da moda feminina. Inserida no segmento competitivo e dinâmico que é o de confecções, visto que as tendências da moda, além de não encontrarem barreiras, mudam a uma velocidade tal que a antecipação de tendências tornase uma das principais estratégias competitivas deste mercado, a empresa em foco objetiva ser uma conceituada empresa no segmento de moda, com produtos e serviços que encantem, proporcionando prazer e satisfação aos clientes e colaboradores.

Isto posto, o constante crescimento da empresa, assim como o contínuo desejo de conquistar novos mercados aliado aos conhecimentos que a pesquisadora adquiriu durante o curso de comércio exterior despertaram para a seguinte problemática: Quais estratégias devem ser traçadas para inserir a empresa Toli no cenário internacional?

Para tanto, diante da análise da estrutura interna da referida empresa, foram apontados os pontos fortes e fracos, as oportunidades e ameaças no tocante à inserção da Toli no 
mercado internacional como um todo, sem a especificação de um mercado em especial. Ademais, esta analise interna da empresa também se presta a apontar as variantes a serem observadas em caso de expansão da empresa dentro do território nacional, uma das metas atuais da referida empresa.

Assim, com base no exposto, aponta-se o objetivo geral do presente estudo, a saber: traçar, a partir da análise da gestão interna, estratégias de inserção da empresa no cenário internacional. São ainda objetivos específicos: analisar a estrutura organizacional, focando os diversos setores e suas inter-relações, identificar as limitações existentes no cerne do cenário internacional e verificar as vantagens competitivas que oportunizam sua inserção no mercado externo.

\section{ESTRATÉGIA EMPRESARIAL E VANTAGEM COMPETITIVA}

A competitividade tornou-se uma das preocupações centrais das empresas em todo o mundo. Porter (1986) elucida que o sucesso competitivo de empresas a nível internacional está intimamente ligado a existência de vantagem competitiva, podendo esta traduzir-se em menores custos ou produtos diferenciados e com preços elevados.

Vale salientar, ainda segundo referido autor, que a vantagem competitiva é obtida através da maneira pela qual as empresas se organizam e realizam suas atividade e que sucesso internacional caracteriza-se como a posse de vantagem competitiva frente aos maiores competidores mundiais.

Nesse sentido, tem-se que estratégia competitiva é um conjunto de planos, políticas, programas e ações desenvolvidas por uma empresa ou unidade de negócios para ampliar ou manter, de modo sustentável, suas vantagens competitivas frente aos concorrentes. Caracteriza-se pela conjugação produto/mercado, isto é, a especificação dos produtos com os quais a empresa pretende atingir seus objetivos e dos mercados onde ela pretende operar para colocá-los ou vendê-los.

Na visão de Porter (1986), a melhoria e inovação em métodos e tecnologia é responsável em grande parte pelo crescimento econômico, exigindo investimentos continuados em pesquisa, capital físico e recursos humanos, auferindo vantagens competitivas para empresas e nações.

É importante salientar que as diferenças nacionais de caráter e cultura destacam-se como fundamentais para o sucesso das empresas locais no mercado internacional, e não estão suscetíveis de ameaças por parte da competição internacional.

Quanto aos fatores estruturais relacionados à competitividade das empresas, sabiamente, Porter (1986) estabeleceu que a estratégia competitiva prescinde um conhecimento detalhado da estrutura da indústria onde a empresa está inserida, assim como uma análise da maneira pela qual esta se modifica. Neste âmbito, o autor enumera forças competitivas presentes em qualquer indústria, a saber: a ameaça de novos entrantes, a ameaça de novos 
produtos ou serviços, o poder de barganha dos fornecedores, o poder de barganha dos clientes e a rivalidade entre concorrentes existentes.

\title{
RECURSOS HUMANOS
}

A gestão de pessoas ou recursos humanos possui a função de gerir e administrar o componente pessoal da organização. Faz-se conveniente a exposição do conceito estabelecido por Chiavenato (2005, p. 10), a saber: "gestão de pessoas é a função que permite a colaboração eficaz das pessoas para alcançar os objetivos organizacionais e individuais". Refere-se o RH ao modo como a organização opera suas atividades de recrutamento, seleção, treinamento, remuneração, avaliação, capacitação, benefícios sociais, entre outros.

Nesse sentido, vale destacar a importância de transformar os recursos humanos em um componente estratégico da empresa, pois a manutenção do RH é indispensável para assegurar que os recursos materiais, financeiros e tecnológicos sejam utilizados de maneira eficiente e eficaz.

\section{MARKETING}

Marketing é a função empresarial que cria continuamente valor para o cliente e gera vantagem competitiva duradoura para a empresa através da gestão estratégica das chamadas "variáveis controláveis", a saber: o produto, o preço, a comunicação e a distribuição.

Consoante Zela, 2002, marketing é:

\begin{abstract}
Uma via de duas mãos entre o Mercado e as Organizações. Elas buscam, numa primeira fase, no mercado, informações necessárias sobre seus desejos e suas necessidades. Nos passos seguintes, passam a oferecer ao mercado os produtos e serviços, de acordo com os desejos e as necessidades dos clientes, tendo como retorno: recursos financeiros e clientes satisfeitos (ou seguidores, correligionários, torcedores, fãs), dependendo das características da organização.
\end{abstract}

Nesse sentido, o objetivo do marketing gira em torno não só da satisfação do cliente, vai além, visa "encantar" o comprador. Para isso, entretanto, deve o profissional de marketing tentar compreender as necessidades, desejos e as demandas do mercado-alvo. Note-se que, "mais do que simplesmente aplicar ferramentas, o empresariado precisa empregar os conceitos do marketing e procurar atender o melhor possível seus clientes" (ZELA, 2002).

Como raras são as empresas que conseguem satisfazer a todos em um mercado, observa Kotler, que, em geral, as empresas optam pela segmentação do mercado. Sendo assim, elas "identificam e traçam os perfis de grupos distintos de compradores que poderão preferir ou exigir produtos e mix de produtos variáveis" (KOTLER, 2000, p. 30). Note-se que mix de 
produtos é o conjunto de ferramentas que a empresa utiliza para perseguir seus objetivos de marketing no mercado alvo. Vale salientar ainda que estes seguimentos de mercados podem ser identificados analisando-se diferenças demográficas, pscicográficas e comportamentais existentes entre compradores.

\section{A IMPORTÂNCIA DAS INFORMAÇÕES E O MARKETING DE RELACIONAMENTOS}

Sabendo que a empresa deve estar sempre em sintonia com os desejos reais e potenciais do seu público alvo, com o intuito de satisfazê-lo, observa-se a importância da informação nesse sentido.

Kotler (2000), crê que a informação pode ser entendida como o "feedback" que o cliente oferece ao mercado. Esta informação abarca as opiniões do cliente acerca do produto e/ou serviço, e também se este conseguiu ou não atender às necessidades que deveria, entre dados similares.

Visto que é através da informação fornecida pelos clientes que a empresa pode aperfeiçoase e, inclusive criar novos produtos, vê-se o quão vital esta função é para a empresa, pois é através da informação que o mercado poderá descobrir quais os desejos e necessidades dos compradores e criar meios para satisfazê-los.

Cides (1997) acredita que o marketing de relacionamento é uma tendência no mundo atual, este objetiva estabelecer relacionamentos mutuamente satisfatórios no longo prazo com clientes, fornecedores e distribuidores, a fim de ganhar e reter sua preferência e seus negócios no longo prazo, criando, dessa forma, uma rede de marketing.

Nesse sentido, vê-se que a globalização dos mercados e a conseqüente desfronteirização mundial deram causa a proliferação de uma concorrência feroz, ou seja, rivais reais ou potenciais de uma empresa. E, neste cenário, a parceria torna-se um diferencial.

Deve-se ter em mente que quando uma empresa conquista e fideliza um cliente, ela beneficia-se não só da compra que ele realizou "hoje", e sim de todas que ele realizará até o fim de sua vida. Da mesma forma acontece com os fornecedores e distribuidores ao fidelizarem uma relação. Com a conquista de um parceiro fiel, a empresa conseguirá vantagens que poderão coloca-lá em uma posição diferencial frente aos concorrentes.

\section{A MARCA}

Neste cerne de competitividade, a importância da fidelização toma proporções significativas, especialmente com relação à marca. França (2000) observa que, com o avanço da ciência em determinar os atributos influenciadores da decisão de compra, vê-se que no aspecto psicológico, a marca sobrepõe-se ao produto. 
Nesse sentido:

Fica evidente que a atração que a marca exerce é a principal maneira de garantir a liderança de mercado, uma marca bem construída traz diferenciação e valor para o negócio. A marca também é o maior patrimônio que se pode criar e desejar, ela estabelece um elo com o consumidor, que vai muito além da qualidade do produto e, é esse envolvimento que vai garantir a lucratividade. (MARTINS, 1999, p. 17.)

Assim, uma marca conhecida tem maior possibilidade de ser escolhida porque o consumidor da preferência ao produto que lhe é familiar. Note-se que, em um mercado competitivo, as marcas conhecidas serão aquelas que merecerão a preferência do consumidor, em detrimento de todas as que são desconhecidas.

\section{PRODUÇÃO}

De uma forma geral, a administração da produção é a função administrativa responsável pela produção de bens e serviços. Slack (2002) crê que a produção é a função central das organizações já que é aquela que vai se incumbir de alcançar o objetivo principal da empresa, o seja, sua razão de existir. Nesse sentido, pode-se inferir a importância vital da administração da produção em uma empresa.

A administração da produção preocupa-se com o planejamento, a organização, a direção e o controle das operações produtivas, de forma a se harmonizarem com os objetivos da empresa, conforme conceito de Moreira (2004).

O planejamento, ao estabelecer linhas de ação, serve de instrumento basilar para as atividades futuras. A organização visa organizar coerentemente os recursos produtivos, a saber: a mão de obra, as matérias primas, os equipamentos e o capital. A direção transforma planos em atividade reais. Finalmente, o controle envolve a avaliação do desempenho de toda a organização.

Vale salientar que a administração da produção participa da escolha dos critérios estratégicos, definindo como focar seus recursos operacionais para dar suporte à estratégia competitiva da empresa, visando transformar as próprias operações em fonte de vantagem competitiva.

\section{TERCEIRIZAÇÃO DA PRODUÇÃO}

Terceirizar é o ato de transferir a responsabilidade por um serviço, ou por determinada fase da produção ou comercialização, de uma empresa para outra. Nas palavras de Perez (2003), a terceirização é o ato pelo qual a empresa produtora, mediante contrato, entrega à outra certa tarefa (atividade ou serviços não incluídos nos fins sociais da empresa), para que esta os realize habitualmente. 
Nota-se, que a terceirização contribui para uma redução no custo dos recursos humanos e materiais, e propicia uma maior flexibilidade na adequação desses recursos às direções estratégicas das organizações. A terceirização combina redução de custos com flexibilidade da organização, buscando qualidade, produtividade e competitividade.

\section{LOGÍSTICA}

A Logística é a área da administração responsável pelo transporte e armazenamento das mercadorias. Conforme conceito do site Canal do Transporte ${ }^{1}$, a logística é o processo de planejamento, implementação, controle do fluxo e armazenagem eficientes de matériasprimas, estoque em processo, produto acabado e informações relacionadas, desde o ponto de origem até o ponto de consumo, como o objetivo de atender aos requisitos do cliente, em uma mesma organização.

As constantes mudanças econômicas e tecnológicas vêm aumentando o grau de importância das operações de logísticas de uma empresa, chegando ao ponto de a logística atualmente ser considerada um fator vital no tocante à competitividade. As mudanças econômicas criam novas exigências competitivas, enquanto mudanças tecnológicas tornam possível o gerenciamento eficiente e eficaz de operações logísticas cada vez mais complexas.

De uma forma geral, existem ainda mais fatores que influenciam a gestão logística, como elucida Dornier (2000), estes fatores podem ser: o mercado, que muda sob a influência de produtos, necessidades de clientes, entre outros; a concorrência, que incita as empresas a implementar suas cadeias logísticas ;as regulamentações governamentais, como por exemplo a exigência de que os fabricantes recolham a embalagem de seus produtos, como ocorre na Europa, entre outros.

\section{METODOLOGIA}

À luz da investigação científica, primordialmente, deve sempre ser estabelecido o tipo de pesquisa a ser utilizado, assim como o universo e a amostra a serem abordados. É o que se fará a seguir.

\section{CARACTERIZAÇÃO DA PESQUISA}

Consoante os ensinamentos de Vergara (1997), sabe-se que a pesquisa, quanto aos fins pode ser classificada como: exploratória, descritiva, explicativa, metodológica, aplicada ou intervencionista.

$1 \quad$ www.canaldotransporte.com.br/letral.asp 
O presente estudo foi realizado mediante uma pesquisa exploratória-descritiva. Exploratória porque embora haja um número significativo de estudos que trate da inserção no mercado externo, não verificou-se a existência de trabalhos que abordem o tema sob a ótica da Toli, empresa foco deste projeto.

Caracteriza-se a presente pesquisa como descritiva visto que abordou o cenário da empresa supracitada, focando, a priori, a análise de sua estrutura interna como um todo, assim como as inter-relações existentes entre seus diversos setores, para então partir para uma análise macro, estudando sua inserção no mercado internacional.

Quanto aos meios, a pesquisa foi bibliográfica, documental e de campo. Foi realizada, para a construção do aporte teórico, uma pesquisa bibliográfica, abarcando uma literatura pertinente ao tema. Ademais, foi a pesquisa de campo ao passo que as informações serão buscadas diretamente com o grupo de interesse acerca dos dados que se deseja obter. Para tanto, foram visitadas as instalações físicas e produtivas da empresa em questão, aplicando um questionário e/ou entrevistando diretamente os responsáveis pela mesma.

Finalmente, utilizando-se das técnicas de estudo exploratório-descritivos o presente projeto propôs a realização de um estudo de caso tanto de caráter exploratório como descritivo, visto que pretendeu descrever toda a estrutura interna da empresa, focando-se os diversos setores organizacionais, assim como a inter-relação entre eles, bem como se propôs-se a traçar e investigar, a partir do suporte da análise referida, as estratégias de inserção da empresa no mercado externo.

Yin (2005) afirma que, em geral, os estudos de caso representam a estratégia preferida quando se colocam questões do tipo "como" e "porque" e quando o foco se encontra em fenômenos contemporâneos inseridos em algum contexto da vida real.

\section{UNIVERSO E AMOSTRA}

Segundo elucidações de Vergara (1997), o universo da pesquisa refere-se ao grupo ou grupos diretamente envolvidos na pesquisa, dessa forma, note-se que o universo da investigação em questão limita-se à empresa Toli, o objeto central do estudo, sendo analisada, como referido, sua estrutura interna, assim como foram identificadas suas limitações e vantagens competitivas no que concerne ao mercado internacional.

\section{DEFINIÇÃO DOS INSTRUMENTOS DE PESQUISA}

Com o intuito de atender aos objetivos propostos, foi utilizada a pesquisa bibliográfica, abarcando a literatura indicada para os assuntos relacionados ao tema do projeto, sendo privilegiados livros, periódicos e páginas de web sites, que, como fonte de dados secundários, se constituiu no aporte teórico do estudo. Paralelamente, foi realizada também um contato direito com a empresa, para obtenção de dados primários, através de 
formulários e/ou entrevistas. Vale salientar que, quanto pertinente, foram também utilizados documentos.

\section{A EMPRESA}

A Empresa Toli foi criada no ano de 1992 e atualmente é destaque no mercado da moda feminina, sendo reconhecida pelas peças diferenciadas que conquistam cada vez a mulher brasileira. Produzindo e comercializando bens de consumo opcional, e contando atualmente com 26 lojas, estrategicamente localizadas, englobando 12 estados, sendo 12 lojas próprias e 14 franquias.

Mediante uma estrutura sólida, organizada, rentável e dinâmica, está presente nas principais cidades do Brasil, sempre exercendo a sua atividade com a responsabilidade social que lhe é peculiar. A Toli possui três diretores sócios, a saber: Amauri Fonseca, Michelle Fonseca Geppert e José Humberto Fonseca.

Faz-se necessário mais algumas especificações quanto à empresa, a saber: sua marca, "Toli", remonta à Ilha Toli localizada na Indonésia. Note-se que tal nomenclatura não foi produto de uma pesquisa realizada junto ao consumidor, mas, obra própria da criatividade do empresário, sendo assim caracterizada como uma marca de família. A empresa possui como missão "Ser uma conceituada empresa no segmento de moda, com produtos $e$ serviços que encantem, proporcionando prazer e satisfação aos clientes e colaboradores".

A Toli vive uma nova fase de expansão da rede de lojas. Desde 2004, a abertura de novas franquias já tem mostrado um cenário bastante otimista. Além do sistema de franquias, a partir de 2005 a Toli iniciou um processo de expansão para todo o Brasil. Atualmente a Toli conta com lojas espalhadas por diversas regiões do país, como em Belo Horizonte, Manaus, Belém e Vitória, além de cidades destaque no cenário nordestino, como Salvador, Recife, Fortaleza, João Pessoa, Maceió, Aracaju, São Luís, Campina Grande, Mossoró e, onde tudo começou, Natal.

\section{ANÁLISE E INTERPRETAÇÃO DOS DADOS}

Como supracitado, este projeto possui como foco a empresa Toli e a análise das variáveis para sua possível inserção no mercado externo. Entretanto, para que esta análise seja possível, faz-se necessário um estudo acerca da estrutura interna desta empresa de moda feminina. De posse deste estudo da estrutura interna, a pesquisadora possuirá embasamento suficiente para estabelecer os pontos fortes e fracos e as oportunidades e ameaças que a Toli encontrará no mercado internacional.

Sendo assim, foram estudados, no que concerne à estrutura interna, pontos acerca das estratégias empresariais adotadas, de como são gerenciados os recursos humanos, o setor de marketing, o setor produtivo e como é operacionalizada a logística da Toli. 
A organização Toli é composta pelas lojas Toli, ou seja, os pontos de venda; pela fábrica Toli, localizada no Distrito Industrial de Macaíba, e pelo sistema franchising Toli de serviços referente às lojas franquiadas.

\section{ESTRATÉGIA}

Em termos de planejamento estratégico empresarial a Toli destaca-se por ser uma empresa que prioriza o planejamento em diversos momentos, abarcando diferentes períodos temporais. Dessa forma, a empresa possui um planejamento a longo prazo, abarcando um espaço temporal de dez anos, com base nas necessidades da cada área, onde são estabelecidas as metas a longo prazo. Dentro das metas estabelecidas por decênio, são estabelecidos planos anuais, contendo um planejamento a médio prazo.

Todavia, os mais importantes planejamentos ocorrem a nível semestral, a curto prazo, com a elaboração de planos de ação por coleções. Sabe-se que as empresa de moda e confecções em geral, incluindo a Toli trabalham com duas coleções por ano, a saber: a coleção primavera/verão e a coleção outono/inverno. Nesse sentido, aponta-se que é neste planejamento semestral realizado por coleção que são estabelecidos em minúcias os planos de ação da empresa. São definidas questões acerca de vendas, escolha e desenvolvimento de novas peças, assim como referentes à produção, ao marketing, às, finanças e, inclusive, acerca a abertura de novos pontos de venda.

A formulação das estratégias é realizada pela diretoria, com o envolvimento de determinados colaboradores. Vale apontar que a diretoria é composta por três diretores sócios, todos possuindo nível superior. Findo este processo de planejamento, os responsáveis pelos diversos setores da empresa ficam incumbidos de passar as informações acerca do plano de ação estabelecido para os funcionários de seu setor, deixando, dessa forma, toda a organização consciente das metas a serem seguidas. Nesse sentido, nota-se que ao transmitir estas informações, os gerentes setoriais tem conhecimento necessário e o comprometimento prévio com as novas estratégias, determinando as necessidades de cada um para o seu cumprimento, visando a coerência entre as estratégias e as necessidades das partes interessadas e o estabelecimento do compromisso mútuos.

Vale salientar que nestas decisões de planejamento são consideradas especialmente fatores como as tendências da moda, no momento do desenvolvimento de uma coleção específica, assim como as datas comemorativas que ocorrerão no momento da referida coleção, pois sabe-se que datas como natal, ano novo e dia dos namorados são períodos de alta sazonalidade no que se refere às vendas no mercado de confecções. Ademais, são levados em consideração também fatores externos, como a concorrência no setor da atuação, as oportunidades de novos negócios como abertura de novos pontos de vendas, e as necessidades dos clientes e do mercado em potencial. Assim como fatores internos, como estrutura, tecnologia e pessoal, bem como as analises das informações qualitativas, que também são pontos importantes a serem considerados ao se formularem estratégias.

A Toli possui como principal estratégia a antecipação das coleções, assim como a maioria das empresas que possuem como objeto a moda feminina. A tendências das coleções neste 
mercado específico, são ditadas por países ícones da moda, em especial as cidades da Europa, com Madri, Londres, Milão e Paris. Sendo assim, como apenas absorvem as tendências e criam suas coleções a partir dos conceitos destas, todas as empresas de moda feminina possuem as mesmas "fontes" de informações. Com o intuito de diferenciar-se, a empresa deve lançar sua coleção primeiro que os concorrentes, pois, dessa forma, estará oferecendo primeiro as novidades às suas clientes.

Outra significativa vantagem competitiva da empresa caracteriza-se por ter $\mathrm{o}$ desenvolvimento constante de novos produtos, de forma que toda a semana chegam às lojas Toli de todo o país novas peças. Esta estratégia atraí constantemente os clientes, que estão sempre em busca de novidades, além de colocar a empresa a frente de seus concorrentes, que trabalham com um único mix de produtos durante toda a coleção.

Também a utilização de um software especializado nas diversas operações da empresa lhe conferem uma vantagem competitiva significativa. Note-se que através do Sistema Expert, o software de varejo desenvolvido especialmente para a Toli, há o fornecimento de informações de todas as partes da organização, o que está sendo produzido, vendido, as saídas e as entradas, e por meio dos números e dos relatórios dos resultados emitidos por este sistema, se estabelecem quadros comparativos, como resultados do desempenho no dia, semana, mês, ano, e determinado período do ano ou de escolha para se comparar os resultados e o que determinava as estratégias e as metas que foram determinadas.

Outro ponto importante a ser considerado é a questão da escolha do mix de produtos a ser selecionado para cada loja Toli, incluindo as franquias. Note-se que este mix de produtos era estabelecido exclusivamente pelo empresário Amauri Fonseca. Vale salientar que referido mix de produtos é revisto e analisado semanalmente, possibilitando mudanças e soluções rápidas e eficazes.

Tal cenário conferia à Toli uma limitação, pois que o empresário despendia grande parte de seu tempo nestas ações, diminuindo o tempo que poderia estar focado em decisões estratégicas mais significativas. Entretanto, o cenário referido já passa por mudanças, ao passo que o empresário já é auxiliado na tomada dessas decisões por um funcionário especializado, reduzindo, dessa forma, as limitações acima citadas.

O cenário ideal caracteriza-se pela utilização de funcionários competentes e especializados que realizem estas ações pelo empresário, de modo que o mesmo apenas aprovasse as decisões realizadas pelo grupo. Note-se que o acompanhamento contínuo do mix de produtos e dos estoques das diversas lojas Toli consubstanciam-se em informações a serem consideradas nas diversas decisões estratégicas a serem realizadas pela empresa em questão.

\section{RECUSOS HUMANOS}

O fator humano consubstancia-se em um ponto decisivo no sucesso de uma organização, especialmente em uma economia globalizada, onde as técnicas tornam-se cada vez mais parecidas e os produtos cada vez mais semelhantes. 
Atualmente a empresa possui cerca de 290 funcionários próprios, destes, 170 trabalham na Fábrica Toli e 120 operam nas lojas. Vale apontar que somam-se à estes números os 120 funcionários que operam nas lojas franquiadas.

Como já citado no ponto referente à estratégia, nos planos estratégicos de $\mathrm{RH}$, realizado a cada coleção, é estabelecido o número de funcionários, de acordo com a sazonalidade do mercado.

O recrutamento na empresa ocorre do forma diversificada, sendo constatado que a mesma opera com diversas ferramentas visando a consecução deste fim. Assim, a Toli utiliza-se de anúncios em jornais e revistas especializadas, agências de recrutamento, contatos com universidades e escolas e apresentação de candidatos por indicação de funcionários.

A Toli, prioriza o recrutamento interno na consecução do preenchimento de vagas na empresa, especialmente para os cargos de gerência e supervisão, fazendo com que seja conferido privilégio aos funcionários já existentes na empresa. Esta priorização acaba gerando no funcionário um sentimento de segurança dentro da empresa, assim como contribui para a motivação do funcionário, conferindo-lhe perspectiva que poderá crescer cada vez mais dentro da empresa. Todos estes fatores fazem com que os funcionários se envolvam cada vez mais com a empresa, assim como possibilita que eles percebam que o sucesso da empresa irá refletir em seu respectivo sucesso.

Um fator importante relacionado ao setor de RH é a socialização do funcionário recém contratado na empresa, nesse sentido, visualizou-se que a Toli integra o novo funcionário à organização através de visitas ao processo produtivo e aos setores administrativos, caso o cargo relacione-se às funções de escritório, e através de treinamentos em todos os setores da loja, caso o cargo relacione-se às funções de loja.

Ocorre ainda um treinamento dentro setor de trabalho, supervisionado pelo encarregado do setor em questão. Note-se ainda que a socialização ocorre durante o treinamento, composto por três dias, onde são passados para os novos funcionários todas as normas da empresa, sua missão, visão, princípios, valores e objetivos organizacionais.

Consoante a psicóloga responsável pelo recrutamento e seleção de novos funcionários, não há sistema oficial de avaliação de desempenho dos funcionários. O que caracteriza-se como um ponto fraco da empresa, ao passo que não está avaliando continuamente seus funcionários visando uma melhoria constante. Entretanto, há um processo de capacitação contínuo na empresa, com o estabelecimento de uma programação anual de capacitação para todas as áreas da empresa.

A empresa segue ainda o modelo Adhocrático, consoante a psicóloga responsável pelo setor de RH, construindo uma organização mais autônoma, flexível e descentralizada. Ademais a tomada de decisões depende da área ou setor, podendo ser centralizada ou descentralizada. E, finalmente, no tocante ao tipo de liderança presente, a psicóloga afirmou estarem presentes na empresa os estilos de liderança liberal, onde o líder transfere sua autoridade para os subordinados. E democrático, onde o líder pressupõe alguma 
influencia dos subordinados no processo de decisão. Neste caso, as diretrizes são discutidas pelo grupo, estimulado e assistido pelo líder.

Entretanto, sabe-se que os setores administrativos da empresa ainda caracterizam-se fortemente pela centralização de decisões, o que acarreta em maior morosidade na tomada de decisões dentro da empresa, além de configurar um ponto em desfavor da Toli. Nota-se, porém, que este cenário está sendo gradativamente modificado pela administração da empresa, que busca continuamente uma maior descentralização de algumas atividades da organização.

Por fim, infere-se que a Toli proporciona um ambiente de trabalho favorável, com significativo incentivo e motivação a seus funcionários. São estipuladas remunerações compatíveis com o mercado, algumas inclusive acima do valor de mercado, além de inúmeros benefícios e garantias legais, e adicionais, como planos de saúdes, cestas básicas, tickets alimentação, recompensas não financeiras, como benefícios sociais, programas de qualidade de vida no trabalho, acompanhamento por nutricionista com um excelente refeitório onde todos fazem suas refeições, a presença de um educador físico que trabalha a ginástica laboral e ainda ciclo de palestras e atividades desempenhadas pelos grupos juntamente com a participação da alta administração e da CIPA - Comissão Interna de Prevenção de Acidentes.

\section{MARKETING}

Sabendo que o marketing visa não só satisfazer os desejos do cliente, mas encantá-lo, as ações de marketing são fatores de destaque na Toli.

Os planos estratégicos de marketing são desenvolvidos por semestre, focando cada coleção, a saber: primavera/verão ou outono/inverno. Neste plano são estabelecidos os montantes a serem gastos com o marketing, abarcando a área financeira; como serão distribuídos estes montantes, ou seja, quais os meios publicitários a serem utilizados; quais as campanhas e promoções que a empresa irá desenvolver durante a coleção, entre outros. Note-se que tal plano foca sempre as datas comemorativas presentes em cada período, fatores importantes, que alavanca às vendas. A coleção primavera/verão é marcada pelo alto-verão, o natal e o ano novo, já a outono/inverno possui como datas marcantes o dia das mães e o dia dos namorados.

O público-alvo da Toli é composto por mulheres entre 20 e 40 anos, das classes A e B. É focando este perfil que a Toli desenvolve as suas estratégias referentes ao marketing.

Os meios publicitários mais utilizados pela Toli par atrair seus clientes são outdoors, assim como a publicidade realizada nos próprios pontos de vendas, através, por exemplo, de parcerias com empresas organizadoras de eventos estabelecendo às lojas da Toli como pontos de venda de camarotes de shows e eventos em geral.

Atualmente a Toli vêm trabalhando bastante no intuito de otimizar a fidelização de seus clientes, especialmente através de um tratamento especial, por meio de envio de cartões de 
aniversários e catálogos de coleções. Aliado à tais ações, está sendo realizado um recadastramento de clientes, objetivando estabelecer uma rede de clientes Toli.

Note-se que, quanto ao comportamento pós-venda, à nível fabril, este ainda não existe. A Toli não possui qualquer Serviço de Atendimento ao Consumidor- SAC ou Central de Atendimento ao Consumidor-CAC.

Todavia, nota-se que à nível de vendas existe um certo nível de serviços pós-venda, ao passo que os clientes tem a possibilidade de realizar as trocas de produtos, seja pela existência de defeitos de fábrica ou ainda pela inadequação por tamanho/modelo ou cor ao gosto da cliente. Nas lojas pode-se ainda efetuar sugestões ou críticas à empresa.

De fato a Toli, como possui lojas espalhadas por 12 estados em diferentes regiões do países, começou a necessitar de uma adequação no tocante à seus produtos neste outono/inverno 2007. A coleção primavera/verão não sofre tal influência, visto que no Brasil, estas estações acontecem de forma similar em todas as regiões do país, com características climáticas parecidas.

Todavia, especialmente a estação inverno ocorre de forma destoante nas diferentes regiões do país. O inverno 2007 foi uma estação com temperaturas abaixo do usual nas regiões sul e sudeste do país. Tal cenário gerou, pela primeira vez, uma necessidade por parte da empresa de envio de peças específicas para tais regiões. Note-se que embora não haja ainda a produção de peças específicas para determinadas regiões do país, tal feito será considerado na produção da coleção outono/inverno 2007. Vale salientar ainda que não obstante a não produção de peças exclusivas para regiões diferenciadas, há uma adequação no tocante ao mix de produtos a ser enviado para as lojas Toli.

Na visão do diretor-sócio Amauri Fonseca, o produto Toli diferencia-se dos concorrentes ao passo que caracteriza-se por ser acessível, possuir alta qualidade e conceitos diferenciados, refletindo as ultimas tendências do mercado.

Note-se que, ainda consoante o empresário, a exclusividade não o diferencia dos concorrentes, embora seja uma característica importante do produto, pois reflete-se em uma estratégia comum a diversas empresas do mercado moda feminina.

Visando conhecer seu mercado e mensurar a aceitação no mercado, a empresa realiza pesquisas mercadológicas anuais, através de uma empresa privada especializada, objetivando obter informações acerca da empresa, assim como acerca de seus concorrentes.

Como a empresa detém diversas lojas, espalhadas por 12 estados brasileiros, é difícil estabelecer pontualmente quais os principais concorrentes da Toli, seja por seu número significativo, seja pela diversidade de lojas concorrentes. 
No que se refere ao design do produto, consoante o empresário Amauri Fonseca, o produto Toli destaca-se por ser inovador, sendo desenvolvido por uma equipe de estilo especializada, com o auxílio dos sócios-diretores no processo de desenvolvimento.

Vale apontar que no mercado moda feminina, as tendências das coleções são "ditadas", estabelecidas pelas capitais da moda, como Nova York, Madri, Milão e Paris. Cabendo ao Brasil absorver estas tendências e criar os produtos nacionais. Ao reverso ocorre com a moda praia, a qual as tendências são estabelecidas por países como o Brasil, por ser referência neste mercado.

\section{PRODUÇÃO}

Como todas as decisões realizadas na Toli, as referentes à produção são realizadas pela diretoria, como supracitado, composta por três diretores sócios e socializadas de forma setorial, de forma que todos da organização tomem ciência e se envolvam com as metas estabelecidas.

A fábrica Toli possui uma capacidade produtiva significativa, infelizmente tais dados não poderão ser divulgados pelo empresário a título de segurança empresarial. Todavia, embora com tal capacidade produtiva, a fábrica não consegue suprir a demanda das vinte e seis lojas Toli espalhadas por todo o país. Nesse sentido, os empresários optaram pela terceirização de parte da produção. Consoante Amauri Fonseca, 20\% (vinte por cento) da produção das peças é atualmente terceirizada, englobando calças jeans e tecidos leves. Vale salientar que esta terceirização é realizada por diversas empresas.

Note-se ainda que apenas a confecção das peças é terceirizada, ficando a equipe de design da Toli responsável por todo o desenvolvimento das peças da empresa. Ao final do processo de decisão de quantas e qual o mix de produtos a serem produzidos, a Toli envia para as fábricas terceirizadas os modelos a serem fabricados.

Ademais, note-se que, em termos de produção, os períodos de sazonalidade são os de outubro/novembro e fevereiro/março.

Os principais insumos da Toli são malhas em geral, produtos que caracterizam-se por possuírem diversas alternativas de fornecimento, além de facilidade à estas fontes de fornecimento, podendo ser obtidos através de representantes comerciais ou até mesmo direto com o fabricante.

Sendo assim, os fornecedores dos insumos utilizados na produção da empresa são as principais empresas têxteis do país, localizadas especialmente no eixo sul-sudeste, destacando-se oi estado de São Paulo.

A indústria da moda não requer uma tecnologia muito avançada, ao passo que no cenário de confecções o ponto forte no tocante à produção ainda é a mão de obra especializada. 
Ademais, por este mesmo fator, a tecnologia referente às maquinas de confecções não tem avançado muito nos últimos anos.

Sabe-se que a localização de uma unidade fabril é uma decisão importante para uma organização. Nesse sentido, a decisão pela construção da fábrica Toli no Centro Industrial de Macaíba foi permeada por significativas vantagens. Por ser um centro industrial, o município de Macaíba optou pela doação do terreno, além concessão de incentivos físcais por parte do governo, visando o desenvolvimento da região, aliado à criação de empregos para a população. Note-se que tais incentivos, além de conferirem oportunidade de desenvolvimento para as localidades próximas, possibilitam à empresa um diferencial competitivo, possibilitando sua inserção de mercado de forma mais eficiente.

No que se refere à sua estrutura, a Fábrica Toli é composta por três diferentes prédios: pela unidade fabril propriamente dita, onde localizam-se o maquinário e onde a produção é realizada; por um prédio administrativo, composto por escritórios, salas de reunião e os diversos departamentos da empresa; e por um prédio de apoio, onde estão localizados o refeitório e os vestiários, por exemplo.

O processo de desenvolvimento de novas peças é realizado pela equipe de estilo da Toli, com a participação dos sócios diretores nas decisões, e dá-se da seguinte forma: inicialmente surgem as idéias, através da Criação, Pesquisa e Desenvolvimento do Produto, que depois de aprovado, passa para fase de Modelagem e Plotagem (risco) que, faz um levantamento de todo matéria prima necessária para sua fabricação, por meio de uma análise econômica, onde se observa-se a viabilidade de produção de determinada peça.

Depois de fabricadas, as peças vão para mesa de corte, são cortados todos os tamanhos e tipos de peças e em seguida, elas seguem para os grupos de costura, responsáveis pelas montagens e costuras das peças, seus respectivos acabamentos e controle de qualidade. $\mathrm{O}$ produto acabado vai para expedição, onde serão distribuídos para as lojas.

Após o processo de desenvolvimento, deve ser decidido o mix de produtos a serem confeccionados, assim como a quantidade de peças a serem produzidas. Para tanto é necessária uma previsão da demanda, com o intuto de tentar prever quantas peças serão vendidas, para então produzi-las.

Sabe-se que a previsão de demanda na Toli é realizada com base em históricos de venda, possuindo os mesmos uma certa confiabilidade, já que a Toli é uma empresa madura, com quinze anos de experiência no mercado moda feminina. Aliado aos históricos de venda, são consideradas também a demanda do mercado moda feminina no momento da produção, constantemente acompanhado por toda a equipe Toli.

Contribuindo para realizar um importante trabalho social, os resíduos das aparas de tecido gerados pela produção da Toli são repassado para uma ONG, intitulada Amac Associação dos moradores e amigos de Cauã. A ONG é responsável pela profissionalização de moradores, elevando seu potencial empregatício, e, consequentemente, sua auto-estima. Esse projeto comunitário o qual a organização apóia e assiste, propicia o desenvolvimento social e econômico dos moradores da região. 


\section{LOGISTICA}

Por possuir lojas em diversos estados e diferentes regiões do país, a logística é um fator chave que pode conferir à empresa Toli um diferencial competitivo no mercado.

Como referido anteriormente, a Toli possui um sistema de informação único que auxilia na tomada de decisões dentro da empresa, ao passo que integra as informações de todos os setores da organização para que sirvam de fator basilar para as diversas decisões acerca das operações da Toli.

Também as decisões logísticas utilizam-se de tal sistema necessitam, ao passo que muitos processos da organização interferem nas atividades logísticas e prescindem destas informações.

Como os fornecedores da Toli localizam-se no eixo Sul-Sudeste, e as matérias-primas são transportadas via modal rodoviário, há um dispêndio de tempo significativo, a ser considerado nas decisões e no planejamento produtivo da empresa.

Vale salientar que a decisão de qual a parte que arcará com os custos do transporte da matéria-prima até a fábrica da Toli, que é terceirizado, dependerá do acordo de vontade firmado entre os mesmos. Assim, poderá ser estipulado contrato CIF2 ou FOB3.

Pelo exposto fica evidenciado que referidos termos, como só devem ser utilizados em negociações internacionais que envolvam os chamados transportes aquaviários (marítimo e hidroviário), são utilizados erroneamente em negociações nacionais. Verifica-se que, para a Toli, ao utilizar-se do FOB nas relações com os fornecedores, fica estipulado que o frete será de responsabilidade da empresa Toli, já ao estipular o CIF, a responsabilidade do frete e do seguro, consequentemente, passa a ser do fornecedor.

Interessante se fazerem notar INCOTERMS nas negociações da empresa, visto que a mesma opera exclusivamente no mercado nacional. Pode-se inferir então a interferência clara do comércio exterior nas relações negociais, inclusive as nacionais.

Já no que se refere ao transporte dos produtos da Fábrica Toli às lojas, foi observado que a empresa detém uma frota própria de veículos para realizar tal entrega às lojas localizadas na cidade de Natal. No que se refere às demais lojas, o transporte é terceirizado e ocorre via modal rodoviário. Todavia, existem exceções, como Manaus e Belém, que, pelo difícil acesso via rodovias, opta-se pelo modal aéreo. Vale ainda apontar que, buscando uma maior celeridade, eventualmente o transporte para Belo Horizonte é realizado via modal aéreo, visto que as mercadorias demoram cerca de três dias para chegar à referida cidade via rodovia.

2 Cost, Insurance and Freight

$3 \quad$ Free on Board 
Vale apontar ainda que no tocante aos rótulos, são elaboradas etiquetas e tags por coleção. Todavia, as embalagens, embora ainda sejam produzidas por coleção, a empresa trabalha atualmente no desenvolvimento de uma embalagem única, no intuito de diminuir os custos e desperdícios, visto que as embalagens não utilizadas em uma coleção não poderão ser utilizadas na próxima.

\section{CONSIDERAÇÕES FINAIS}

A internacionalização das empresas brasileiras vem se tornando cada vez mais uma tendência, ao passo que as companhias adotam a inserção no mercado internacional como estratégia empresarial.

Entretanto, em qualquer processo de exportação, é preciso identificar e avaliar pontos fortes e fracos, oportunidades e ameaças de mercado. Note-se que a tomada de decisão quanto à exportação envolve, principalmente, uma análise técnica das vantagens de exportar, a partir de estudos acerca da estrutura interna da empresa que se propõe a desbravar o mercado exterior.

Deve-se ter em mente que a exportação é uma estratégia empresarial, sendo assim, a internacionalização não é saída para crises, e sim uma fator de desenvolvimento da empresa, e como tal, prescinde projetos estruturais e não conjunturais. A exportação realizada com sucesso faz com que a empresa adquira vantagens, especialmente frente aos concorrentes internos, como: redução de custos fixos, operacionais e financeiros, diversificação de mercados e de riscos, melhor desenvolvimento de recursos humanos, aprimoramento da qualidade, incorporação de novas tecnologias, aprimoramento do marketing, dos métodos administrativos e organizacionais e aumento da rentabilidade.

Vale apontar que, no tocante à internacionalização, devem ser cuidadosamente analisados sete principais aspectos. Inicialmente busca-se observar o ambiente de negócios, ou seja, deve-se almejar a perfeita adequação dos objetivos da empresa à realidade que a cerca, seja no âmbito interno, seja no externo. A correta observância do que pode afetar a performance internacional da empresa constitui-se o ponto inicial do processo de exportação. Note-se que internamente há de se verificar movimentos políticos, a regulação aplicada ao comércio exterior, variações cambiais, condições de financiamento e infra-estrutura. Já no que se refere ao mercado internacional, deve ser voltada atenção para o ambiente econômico, político, cultural, legal e social.

A estrutura organizacional é outro ponto a ser observado, pois a competência é uma exigência no mercado externo, e a tolerância a sua ausência é quase nula. Num mercado ferozmente competitivo, como o internacional, espera-se que os "atores", sejam empresas ou governos, enviem profissionais aptos a representar bem o seu país.

Outro fator que demanda atenção como estratégia exportadora é o marketing e o desenvolvimento de produtos, ao passo que a capacidade de adaptação dos produtos nacionais às necessidades externas é imprescindível. Nesse sentido, deve a organização ser capaz de entender as necessidades e mover-se de maneira competitiva a fim de atender à demanda. 
Ademais, exige atenção a questão da logística e condições de entrega, pois o envolvimento com os procedimentos citados confere uma vantagem competitiva a empresa exportadora, ao passo que diversas organizações se esquivam deste serviço por temerem os altos custos dos fretes e pelo receio de envolver-se com mais uma gama de procedimentos complexos.

Um outro fator de demasiada importância é o gerenciamento de riscos, a fím de transformar riscos em oportunidades. Ademais, como citado anteriormente, devem ser observados os aspectos políticos, a fim de ser avaliada a viabilidade da exportação no tocante aos fatores políticos nacionais.

Finalmente, o último aspecto é a estratégia comercial, ou seja, a capacidade das organizações em correlacionar todos os fatores supracitados agregando suas ações.

Isto posto, infere-se que o caminho da inserção global, embora complexo, é plenamente viável, e ignorá-lo é um erro que só o tempo se encarregará de mostrar, pois a internacionalização das empresas é uma tendência mundial, e a competitividade pelos mercados mundiais só tende a crescer.

Nesse sentido, entra em foco o tema do presente projeto, a saber: estratégias de inserção internacional - um estudo de caso da Toli. Como supra observado, faz-se imprescindível uma análise detalhada, do cenário interno e externo à empresa na consecução do objetivo da internacionalização. Ademais, deve ser estudado com detalhes a estrutura interna da organização visando estabelecer os pontos fortes e fracos, as oportunidades e ameaças que a mesma encontrará no mercado internacional, com o intuito de verificar-se a viabilidade da internacionalização da empresa. Observadas estas considerações, se dará início à consecução dos objetivos propostos por este projeto.

A Toli, por ser uma empresa do cluster moda feminina, detém características específicas no tocante ao mercado internacional. O mercado de confecções, no que se refere aos produtos brasileiros, está mais receptivo à moda feminina, e especialmente à moda praia, moda casual e moda jeans wear. Note-se que na moda praia as tendências das estações são estabelecidas pelo Brasil, por ser um país referência neste segmento. No que se refere à moda casual, à jeans wear e aos demais segmentos, verifica-se que há uma competitividade feroz, especialmente por parte de países como a China e a Índia.

Tendo isso em mente, parte-se então para a definição das dificuldades e oportunidades que o seguimento confecções proporciona no mercado internacional. Vale apontar que possuir supracitados países como concorrentes caracteriza-se como uma dificuldade, ao passo que o Brasil não possui infra-estrutura suficiente para concorrer em preço e volume com os produtos chineses e indianos.

Todavia, as empresas brasileiras podem transformar esta dificuldade em oportunidade. Sabendo que o preço não é o diferencial do nosso produto, volta-se para a produção em pequenos volumes, mas com produtos diferenciados, de maior valor agregado. Esta caracteriza-se como a principal vantagem dos fabricantes brasileiros.

O "estilo" brasileiro faz com que o país se projete como pólo de moda, especialmente pela originalidade dos produtos, que conquistam cada vez mais os consumidores estrangeiros. Sendo assim, para uma efetiva conquista do mercado externo, cabem ás empresas de confecções quebrarem o conceito da sazonalidade, e produzirem $\mathrm{o}$ ano inteiro, 
possibilitando o fornecimento à grandes mercados; perceberem a importância da fidelização do cliente e primar pela originalidade, o grande diferencial do produto nacional.

Nesse sentido, a oportunidade gerada para o segmento confecções no mercado internacional exige a presença do estilo brasileiro, aliando irreverência e sensualidade na criação de produtos originais e diferenciados, que se destaquem no mercado externo, da qualidade dos produtos, com modelagens e acabamentos que sigam as exigências internacionais, e, finalmente, da perfeição dos serviços, garantindo a pontualidade das entregas, por exemplo.

Após a observação da viabilidade do mercado brasileiro de confecções no exterior, volta-se para a análise acerca da Toli, verificando as oportunidades e ameaças, assim como os pontos fortes e fracos da empresa foco do estudo em questão quanto à inserção do mercado internacional.

Na consecução da inserção estratégica no mercado internacional, a Toli irá deparar-se com inúmeras ameaças, especialmente levando-se em consideração a atual conjuntura políticoeconômica global.

Como supra estudado, o advento da globalização concorreu para o desenvolvimento de uma feroz concorrência mundial, aliado a uma constante busca por novos mercados consumidores. Nesse cenário, adiciona-se ainda o crescimento econômico de países emergentes, como a China, a Índia e a Coréia do Sul, que se destacam no cenário global como importantes exportadores, com grande potencial de crescimento.

A China, que vêm ocupando espaço de destaque no cenário econômico, aliando altas taxas de crescimento e um significativo aumento das exportações, baseado em vantagens estratégicas como: vastas reservas de carvão mineral para produção de energia, um potencial de recursos humanos significativo, com mão de obra abundante e barata, entre outros. Por estes fatores a China está conquistando cada vez mais mercados, inclusive o de confecções, e tornando-se uma das mais novas ameaças às empresas deste segmento, apresentando produtos a preços baixíssimo, entretanto com pouca qualidade e diversidade.

Outro fator gerador de ameaça é a característica da antecipação de tendências, aliado à estipulação de tendências por países da Europa, já que o Brasil não é referência neste mercado. Como anteriormente citado, as coleções da Toli, assim como das demais empresas brasileiras do segmento moda feminina, são criadas através das tendências lançadas por cidades referências da moda, localizadas especialmente na Europa, como Madri, Milão, Paris e Londres, além de cidades como Nova York, representando a moda norte-americana.

Nota-se que este cenário gera uma ameaça à inserção da empresa no mercado externo ao passo que estas cidades limitam os mercados potenciais para as confecções brasileiras. Visto que a Toli baseia-se nas tendências destes mercados, para então iniciar seu processo de criação e produção de peças, ficando inviável conseguir absorver estas tendências e, simultaneamente, entregar peças, coadunando com as tendências estabelecidas pelas cidades referidas, em uma mesma coleção. 
Ademais, a disparidade climática entre o Brasil e outros países caracteriza-se como outra ameaça do mercado, especialmente quando referem-se a locais de frio intenso, pois a produção da empresa em estudo é adequada a climas mais amenos.

Finalmente, as constantes crises políticas brasileiras, especialmente as crises atuais de corrupção, aliadas as carências do país por reformas estruturais ameaçam a inserção das empresas nacionais no mercado externo, além de concorrer para a diminuição do desenvolvimento econômico do país. Este cenário confere desconfiança aos importadores, dificultando as operações internacionais.

Embora encontre ameaças no mercado internacional, percebeu-se que a presença de oportunidades no tocante à inserção da empresa em questão no mercado externo, especialmente pelos seus produtos diferenciados.

A moda brasileira possui alto potencial competitivo no mercado internacional, especialmente por primar pela originalidade, com peças sensuais, irreverentes e que se destacam no mercado. Nesse sentido, nota-se que a China não representa uma ameaça à Toli, no que se refere à conquista de mercados globais, ao passo que ao primar pelos preços baixos, os produtos chineses caracterizam-se pela ausência de qualidade e pela produção grandiosa. Assim, o produto Toli ao envolver-se em conceitos diferenciados, aliando preços acessíveis e qualidade, além de primar por peças estilizadas e com um maior caráter de exclusividade, visto que não são produzidas em grande escala, destacamse dos produtos chineses, e encontram mercados potenciais significativos no exterior, desenvolvendo peças com um maior valor agregado.

Ademais, apensar da antecipação de tendências e das circunstâncias já descritas, a empresa encontra inúmeros mercados em potencial, especialmente na América Latina, aliando a proximidade territorial com condições climáticas semelhantes. Nesse sentido, vislumbrouse a Venezuela como mercado ideal para a inserção estratégica da Toli no mercado externo, em especial pela proximidade com o Brasil e pela condições climáticas semelhantes, sendo perfeito para o início das atividades da empresa no mercado mundial. Todavia, devem ser levados em conta os aspectos legais, econômicos e políticos, a fim de coadunarem com estes fatores.

Internamente, foram observados pontos fortes, que impulsionam uma inserção de sucesso da empresa, a saber: a alta qualidade dos produtos, aliado aos conceitos e cortes diferenciados, sempre condizentes com as mais recentes tendências da moda, concorrendo para o destaque das peças; ademais, o fato de a empresaria primar por uma estratégia de gestão eficiente, com planejamentos constantes e valorizando uma liderança estimulante e participativa, além da a motivação dos funcionários, contribui para seu sucesso; aliado a estes fatores têm-se a busca constante pela fidelização dos clientes e pela construção de parcerias concretas com os fornecedores contribuem para o sucesso da empresa e elevam seu potencial para o mercado internacional.

Ademais, a preocupação constante com as mudanças do mercado e com a trajetória dos concorrentes, através da realização de pesquisas mercadológicas freqüentes, a utilização das tecnologias de informação para otimizar todos os processos presentes na empresa e a própria localização da Fábrica Toli e os ambientes harmônicos das lojas conferem vantagem à empresa no mercado interno e externo. 
Note-se que um dos mais significativos pontos fortes da empresa é a constante preocupação com a responsabilidade social. Como supra apontado, a Toli auxilia projetos sociais em cooperação com a ONG Amac, viabilizando novas oportunidades para membros de populações carentes do Rio Grande do Norte, através, por exemplo, de capacitação profissional. Sabe-se da repercussão positiva da responsabilidade social no mercado externo. Destarte, tal ponto forte confere à empresa uma real vantagem no cerne do cenário internacional.

Todavia, a empresa apresenta alguns pontos fracos, a serem corrigidos visando sua inserção eficiente no mercado externo. Entre eles destaca-se a forte tendência de centralização das decisões dentro da empresa, o que pode gerar uma lentidão nos processos, não admitida no âmbito internacional. Ademais, a empresa ainda foca sua produção ao clima nordestino, fato que começou a surtir resultados negativos no mercado interno, visto que foi percebida a necessidade de envio de peças mais adequadas ao frio do Sul e Sudeste no inverno 2007. Note-se que esta restrição ao clima pode gerar limitações à empresa, especialmente no que se refere à busca por novos mercados, sejam internos ou externos.

Isto posto, infere-se a viabilidade da inserção da empresa em questão no mercado externo, comprovado pelas inúmeras oportunidades e pontos fortes apresentados pela empresa. Dessa forma, conquanto alie os produtos com estilos diferenciados, qualidade, serviços eficazes às considerações aqui presentes, a possibilidade de a empresa obter sucesso no mercado internacional é significativa.

Finalmente, chega-se à conclusão de que é possível avanças as fronteiras, todavia, devem ser analisados todos os pontos fortes e fracos, oportunidades e ameaças com antecedência, para então serem corrigidas as fragilidades e enaltecidas as vantagens, coadunando com uma inserção de sucesso.

\section{REFERÊNCIAS BIBLIOGRÁFICAS}

1. CÂMARA BRASIL CHINA. Disponível em: <www.ccibc.com.br〉. Acesso em: 20 jul. 2007.

2. CANAL DO TRANSPORTE. Disponível em: <www.canaldotransporte.com.br/letral.asp>. Acesso em: 12 jan. 2007.

3. CAPITAL DE RISCO. Disponível em: < www.capitalderisco.gov.br $>$. Acesso em: 01 dez. 2006.

4. CIDES, Sérgio J. Introdução ao Marketing. São Paulo: Atlas, 1997.

5. CHIAVENATO, Idalberto. Administração e Recursos Humanos: Fundamentos Básicos. 5. ed. São Paulo: Atlas, 2003.

6. Gestão de Pessoas. São Paulo: Atlas, 2005.

7. COUTINHO, L. G.; FERRAZ, J. C. Estudo da Competitividade da Indústria Brasileira. 3. ed. Campinas: Papirus, 1995.

8. DORNIER, Philippe-Pierre; et al. Logística e Operações Globais: Texto e Caos. São Paulo: Atlas, 2000. 
9. FERREIRA, A.A. Gestão Empresarial: de Taylor aos nossos dias. São Paulo: Pioneira, 1997.

10. FRANÇA, Sônia Maria Mendes; CORNETA, Alexandre Luiz; MARTINS, Daniel. Caracterização Do Perfil Do Público-Alvodo Catuaí Shopping Center Londrina. Disponível

em: <http://www.portaldomarketing.com.br/Artigos/Catuai\%20Londrina.ht>. Acesso em: 12 jan. 2007.

11. GHEMAWAT, Pankaj. A Estratégia e o Cenário dos Negócios. São Paulo: Bookman, 2000.

12. KOTLER, Philip. Administração de marketing. 10. ed. São Paulo: Prentice Hall, 2000.

13. MARTINS, José. A Natureza Emocional da Marca: Como encontrar a imagem que fortalece sua marca. São Paulo: Negócio Editora, 1999.

14. MAXIMIANO, Antônio C. A. Introdução à administração. 5. ed. São Paulo: Atlas, 1995.

15. MINERVINI, Nicola. O Exportador. São Paulo: Makron/McGraw-Hill, 1991.

16. MOREIRA, Daniel. Administração da produção e operações. São Paulo: Pioneira, 2004.

17. MOTA, Paulo Roberto. Participação na Gerencia: uma perspectiva comparada. Revista de Administração Pública. Out./dez. 1981.

18. PEREZ, Fábio Luis. Disponível em: 〈http://teses.eps.ufsc.br/defesa/pdf/9514.pdf〉. Acesso em: 15 maio 2007.

19. PORTER, Michael E. Estratégia Competitiva: Técnicas para análise de indústrias e da concorrência. 30. ed. Rio de Janeiro: Campus, 1980.

20. RODRIGUES, Marcus Vinicius Carvalho. Qualidade de Vida no Trabalho. 4 ed. Rio de Janeiro: Vozes, 1998.

21. RUIZ, Manoel. Globalização. Publicado em 23 nov. 2003. Disponível em: <www.sociedadedigital.com.br/artigo.php?artigo=123>. Acesso em: 02 dez.2006.

22. SEBRAE. Disponível em:< www.sebrae.com.br>. Acesso em: 01 dez.2006.

23. SENGE, P. A Quinta Disciplina. 12. ed. São Paulo: Nova Cultura, 2000.

24. SLAKS, Nigels; CHAMBERS, Stuart; JOHNSTON, Robert. Administração da Produção. 2. ed. São Paulo: Atlas, 2002.

25. VERGARA, Sylvia Costant. Projetos e Relatórios de Pesquisa em Administração. São Paulo: Atlas, 1997.

26. YIN, Robert K. Estudo de Caso. USA: Sage Publications Inc., 1989.

27. ZELA, Douglas. Revista FAE BUSINESS, n.2, jun. 2002. p. 30. Disponível em: http://www.fae.edu/publicacoes/pdf/revista_fae_business/n2_junho_2002/gestao1_afin al_de_contas_oq_e_marketing.pdf. Acesso em: 15 maio 2007. 